\title{
CXXV. CONTRIBUTIONS TO THE STUDY OF BRAIN METABOLISM.
}

\section{CARBOHYDRATE METABOLISM.}

\author{
By ERIC GORDON HOLMES (Grocers' Company Research Scholar) \\ AND BARBARA ELIZABETH HOLMES. \\ From the Biochemical Laboratory, Cambridge.
}

(Received August 28th, 1925.)

In a previous communication [B. E. and E. G. Holmes, 1925] we were able to show that the "resting" lactic acid content of rabbits' brains was greatly reduced, if the animals had convulsed, or were on the point of convulsing, as a result of a dose of insulin.

That the low values obtained as a result of insulin administration might possibly have been due to an increased oxidation of lactic acid as a consequence of the presence of the insulin, is suggested by the work of Neuberg, Gottschalk and Strauss [1923] who demonstrated an increased formation of acetaldehyde (which might have come from the oxidation of lactic acid) in tissue hashes to which insulin had been added. We found, however, reason to suppose that, although reducing substance can be extracted from rabbits' brains after death, none of it (or at most a very small amount) is glucose. Whilst we found that intact or chopped brain does not by itself give rise to increased lactic acid production on standing at body $p_{\mathrm{H}}$, we confirmed the statement of Warburg, Posener and Negelein [1924] that it does so if glucose be added to it. The suggestion therefore presented itself that the "resting" lactic acid values obtained for brain were ultimately dependent on the level of the bloodsugar, and not due to a direct effect of insulin, or any accompanying impurity, on the brain cells.

Since our first experiments, we have found it possible to obtain, by suitable means, values for brain lactic acid very considerably higher than any "normal" values, and this without any marked rise of blood-sugar. In spite of this, however, we are inclined to believe that the lowering of the brain lactic acid after insulin is a consequence of the fall in blood-sugar, and does not occur apart from the latter.

It was at first hoped that it would be possible to plot a brain lactic acidblood-sugar curve. For reasons to be discussed immediately, this could only be done, if at all, by using an unjustifiably large number of animals. It is, however, easy to show that the brain lactic acid does not fall appreciably 
until the blood-sugar has dropped considerably, whilst, provided that the blood-sugar has fallen below about $70 \mathrm{mg}$. per $100 \mathrm{cc}$., the resting lactic acid value is always well below the normal.

The experimental results are arranged in two tables. Table I shows the results obtained from groups of animals from the same litter. (The normal values from animals of the same litter show much less variation than those from animals taken at random.) Table II contains values obtained from animals used for experiments performed with another object, in which the brain lactic acid and the blood-sugar were both determined.

No. $5 \beta$ deserves particular attention. The animal was not starved, and was therefore given a large dose of insulin (30 units). Convulsions took place after 98 minutes. After these had lasted 5 minutes $8 \mathrm{cc}$. of $10 \%$ glucose in normal saline were given subcutaneously. The animal recovered. Twenty minutes later, blood samples were taken, and the animal was killed. The blood-sugar was $119 \mathrm{mg}$. per $100 \mathrm{cc}$., while the brain lactic acid was $56 \mathrm{mg}$. per $100 \mathrm{~g}$. This last value is higher than any obtained for convulsed animals, and is evidently rising towards the normal.

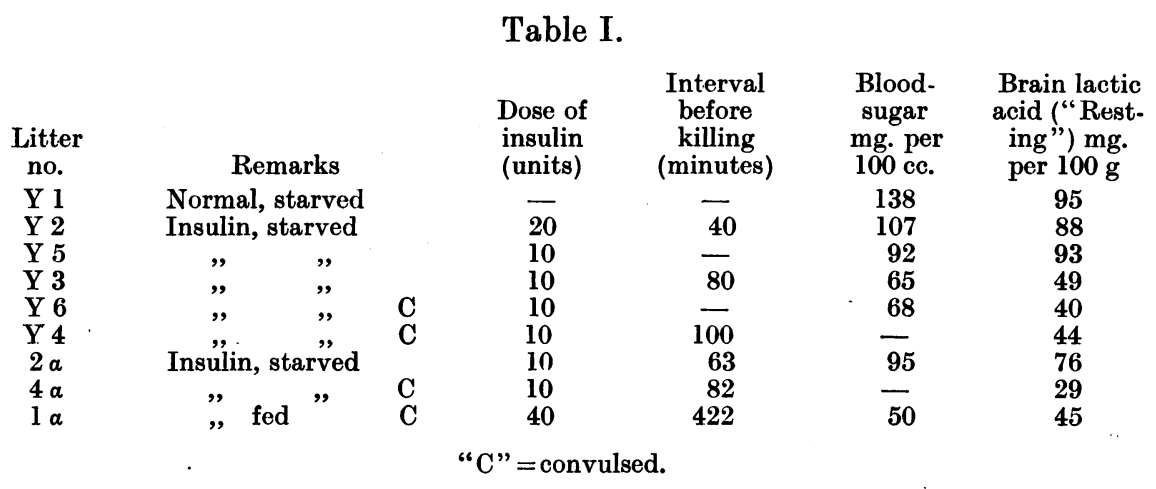

Table II.

\begin{tabular}{|c|c|c|c|}
\hline & \multicolumn{2}{|l|}{$-60-2$} & \multirow[b]{2}{*}{$\begin{array}{l}\text { Resting brain } \\
\text { lactic acid } \\
\text { mg. per } 100 \mathrm{~g} .\end{array}$} \\
\hline & Remarks & $\begin{array}{l}\text { Blood-sugar } \\
\text { mg. per } 100 \mathrm{cc} .\end{array}$ & \\
\hline $\mathbf{X} 1$ & Insulin & 124 & 96 \\
\hline $13 \mathrm{~F}$ & Normal & 150 & 101 \\
\hline $17 \mathrm{D}$ & & 131 & 75 \\
\hline 23 & Insulin & 61 & 44 \\
\hline $5 \beta$ & $\begin{array}{l}\text { Insulin, convulsed. Recovered } \\
\text { with } 8 \text { cc. } 10 \% \text { glucose }\end{array}$ & 119 & 56 \\
\hline
\end{tabular}

The blood was drawn from an ear vein.

Blood-sugar by the method of Hagedorn and Jensen [1923].

Brain frozen and crushed before weighing [B. E. and E. G. Holmes, 1925].

Lactic acid by method of Meyerhof [1920]. (Uncorrected figures.)

Since it is seldom possible to obtain a litter of more than six rabbits, any single series of values is limited to that number. This makes it extremely difficult to hit off any required blood-sugar level, for the animal must be 
killed immediately the sample has been taken, and long before the sugar estimation can be completed.

- It will be observed that the lactic acid does not fall until the blood-sugar is below about $70 \mathrm{mg}$. per $100 \mathrm{cc}$. Since values ranging from 100-75 mg. per $100 \mathrm{~g}$. (we have had two values as low as 65) are obtained for the resting brain lactic acid of normal animals from different litters, it is hardly to be expected than an exact correlation between blood-sugar and brain lactic acid could be found above this level.

The fact that, for instance, rabbit "Y 2 " (Table I) showed no appreciable fall in brain lactic acid 40 minutes after 10 units of insulin, shows that insulin, of itself, exerts no direct effect on the brain lactic acid metabolism.

It is, of course, certain that there are many factors complicating the issue. If the amount of lactic acid formed depends upon the amount of glucose made available via the blood stream, it must vary, not only with the level of the blood-sugar, but also with the rate of blood supply to the brain, and, further, by the rate at which glucose is able to diffuse into the cell, and reach the point at which chemical change occurs. Of these three factors, one only is known, namely, the blood-sugar level.

Apart from these considerations, Hiller and collaborators have recently shown [Hiller, Almer, Linder and Van Slyke, 1925] that only a part of the reducing substance, estimated in blood by the methods in general use, is glucose. A variable but not inconsiderable part of it appears to be some material or materials which is not fermented by yeast, nor destroyed by the glycolytic enzyme of the blood itself. In fact, they suggested that after insulin the glucose content of rabbits' blood may fall to zero, though a very definite reducing power still remains. If these findings be correct, it is hardly likely that the figures appearing in our tables under "blood-sugar" represent at all accurately the glucose content of the blood.

We feel, however, that the experiments here described make it improbable that the fall in brain lactic acid which we observe is due to an immediate effect of the insulin, or of any substance injected along with it, on the brain cells. In the latter connection, it is worth mentioning that in our earlier experiments we used a dried insulin preparation (supplied by Messrs Boots); in those here described, we employed a liquid preparation prepared by Burroughs and Wellcome for clinical use.

\section{SUmmaRY.}

A comparison of the blood-sugar values, and the resting lactic acid content of the brains of rabbits, shows that the fall in the latter resulting from the injection of insulin does not occur until the blood-sugar has reached a fairly low level. At the convulsive or flaccid (pre-convulsive) stage the brain lactic acid content is very small. One experiment indicates that the lactic acid content rises again when the animal has recovered as the result of injection of glucose. 
From these results it appears probable that the fall in the resting lactic acid content of the brain after insulin injection is not due to a direct effect of insulin in promoting increased oxidation of lactic acid, nor to any direct effect of insulin or an accompanying impurity in depressing the production of lactic acid by the brain cells, but is rather caused by the fall in the bloodsugar level, and the resulting shortage of glucose in the brain.

One of us (B.E.H.) is in receipt of a grant from the Medical Research Council.

\section{REFERENCES.}

Hagedorn and Jensen (1923). Biochem. Z. 135, 46.

Hiller, Almer, Linder and Van Slyke (1925). J. Biol. Chem. 64, 625.

Holmes, B. E. and E. G. (1925). Biochem. J. 19, 192.

Meyerhof (1920). Pflüger's Arch. 182, 239.

Neuberg, Gottschalk and Strauss (1923). Deutsch. med. Woch. 49, 1407.

Warburg, Posener and Negelein (1924). Biochem. Z. 152, 309. 